\title{
Current and potential methods for measuring emotion in tourism experiences: a review
}

\begin{abstract}
This study provides an assessment of methods used in existing tourism research to measure emotion and discusses the potential for use of psychophysiological methods such as electro-dermal analysis, facial muscle activity, heart rate response, eye tracking system and vascular measures. Psychophysiological measurement techniques have been reported in the marketing, advertising and media literature; however, to the best knowledge of the authors, no studies are reported in the tourism literature. Instead, studies of emotion in the tourism literature invariably employ self-report questionnaire methods which capture only tourists' high-order emotions and are subject to a variety of forms of bias. Unconscious emotional responses that can provide unbiased portrayal of individuals' initial emotional reactions when exposed to a stimulus have been largely ignored. The paper concludes that studies combining both self-report and psychophysiological measures are needed and areas for future research are discussed.
\end{abstract}

Keywords: tourist emotion; emotion measurement; self-report; psychophysiological measurement of emotion

\section{Introduction}

Understanding the emotions elicited by tourism experiences is an important challenge for destination marketers and indeed all tourism operators (Gretzel, Fesenmaier, Formica, \& O’Leary, 2006). Emotional arousal is a major motivation for the purchase and consumption of products such as sports, plays and travels (Bloch, Sherrell, \& Ridgway, 1986; Goossens, 2000). Tourism produces hedonic consumption experiences (Alistair, 2006), involving adventure, challenge, escape, and fun (Otto \& Ritchie, 1996), happiness (Gretzel et al., 2006) and pleasure (Floyd, 1997). Fantasy, feelings and fun are a central part of hedonic experiences (Holbrook, 2006) and positive and pleasurable emotions and feelings are important components of tourism experiences (Tung \& Ritchie, 2011). Therefore, it is clearly important for both academia and industry managers to better understand the vital role of emotion in customer experiences of tourism. 
Tourism academics have long sought to study the role of emotion in experiences and numerous studies have examined the emotions experienced by tourists before planning, during and after their trip. When planning a holiday tourists are believed to experience a series of positive emotions that play a pivotal role in the decision-making process and final choice of destination (Walters \& Sparks, 2012) and involve fantasy and considerable pleasure (Kwortnik \& Ross, 2007). Due to their importance, emotions have been used as a segmentation variable for leisure services (J. Enrique Bigné \& Andreu, 2004). During the holiday, emotions experienced are an indispensable component of a memorable destination experience (Aho, 2001 ; Mcintosh \& Siggs, 2005), and the intensity of emotions vary during the whole experience (Kyle \& Lee, 2012). After a holiday experience, there is general agreement that emotions significantly influence tourist satisfaction (J. Enrique Bigné, Andreu, \& Gnoth, 2005; de Rojas \& Camarero, 2008; Hosany \& Prayag, 2013; Matzler \& Faullant, 2011) and behavioural intentions such as willingness to pay more (J. Enrique Bigné et al., 2005), intention to recommend (Hosany \& Prayag, 2013) and favourable behavioural intention in general (Tsaur, Chiu, \& Wang, 2007). Further, the emotional associations that the tourists attach to a tourism destination are positively related to satisfactory experience and destination loyalty (Barsky \& Nash, 2002; F. Yuksel, Yuksel, \& Bilim, 2010).

Given the importance of emotions in tourism, the measurement of emotional responses to visitor experiences is a crucial issue as well as being acknowledged as a complex research task (Mauss \& Robinson, 2009). In the past measurement tools used to capture individuals' emotional outcomes in a tourism context have relied entirely on affective reports. In this method, respondents are asked to express their emotional reactions through open-ended questions or rate their emotional state on a set of affective items (Hosany \& Gilbert, 2010; Hosany \& Prayag, 2013; Kyle \& Lee, 2012; Pearce \& Coghlan, 2010; Walters \& Sparks, 2012), an approach collectively termed 'self-report' method (Chamberlain \& Broderick, 2007; Jacobs, Fehres, \& Campbell, 2012; Mauss \& Robinson, 2009; Poels \& Dewitte, 2006; N. Ravaja, 2004; Wang \& Minor, 2008). While useful, such self-report methods may involve cognitive bias (Paulhus, 2002), elicit socially acceptable answers (Wiles \& Cornwell, 1991), or seek responses where respondents may not remember or be aware of the emotions they have experienced (Poels \& Dewitte, 2006).

In other disciplines, researchers have sought to overcome the problems of using self-report data when measuring emotions by using alternative methods. In particular, 
psychophysiological methods have been used to provide a more objective and unbiased approach to track individuals' emotional responses (Morin, 2011; N. Ravaja, 2004). Psychophysiology is the branch of psychology that assesses the variations in the activity of physiological systems evoked by internal autonomic responses (Vögele, 1995). Such measures can be more objective in reflecting individual's emotional responses compared to traditional self-report methods (N. Ravaja, 2004). As autonomic responses are not under voluntary control, they can provide unbiased portrayals of people's initial emotional reactions to a situation or event (Stewart \& Furse, 1982).

In the past, use of psychophysiological methods was not common due to the costly and specialized nature of the measurement equipment. However, the recent emergence of affordable and relatively accessible psycho-physiological equipment such as that used for eye-tracking, electro-dermal and heart rate studies has led to increasing their use in examining consumers' attention, arousal level and emotional valence. A number of studies of customer emotions in the fields of marketing, advertising and media have adopted such psychophysiological methods (Lee, Broderick, \& Chamberlain, 2007), and found them effective in capturing consumers' emotional responses to a service experience and advertising stimuli (Chamberlain \& Broderick, 2007; Micu \& Plummer, 2010; Poels \& Dewitte, 2006; N. Ravaja, 2004; Wang \& Minor, 2008). This suggests that tourism scholars may also benefit from using such methods to measure and analyse tourists’ emotions.

The purpose of this paper is threefold. Firstly the paper presents a definition of emotion and the major approaches to the study of experiences involving emotional responses. Secondly, the paper reviews the tourism literature on emotions highlighting the different theoretical approaches and measurement methods used. Thirdly, this paper proposes five psychophysiological methods (EDA, facial electromyography, heart rate, eye tracking and vascular measure) commonly used in marketing, advertising and media research and discusses their potential for the measurement of tourists' emotions.

\section{The Concept of Emotion}

Before reviewing the specific techniques used to measure emotion, it is necessary to consider the definition of the construct of emotion and thus the methodological implications for measuring this construct. In this section, the definition of emotion and differences amongst 
emotion, affect and mood are discussed, followed by the examination of two dominant approaches to describe emotional responses: the basic emotion and dimensional approaches.

A commonly accepted definition of emotion has proved elusive (Parrott, 2001), and it is clear that emotion is not a simple phenomenon that can be easily observed (Davidson, Bondi, \& Smith, 2005). Emotions arise as a result of an evaluation or assessment of specific stimuli relevant/irrelevant to individuals or groups' goal (Niedenthal \& Brauer, 2012), and are characterized by episodes of intense feelings associated with specific response behaviours (Hosany \& Prayag, 2013). Emotions involve a number of component processes encompassing subjective feelings, expressive motor behaviour, physiological arousal, cognitive appraisal and a behavioural tendency (Frijda, 1986), In a review of over 100 definitions of emotion, Kleinginna $\mathrm{Jr}$ and Kleinginna (1981) found that although disagreements exist about an explicit definition of emotion, most scholars endorse the view that emotions include three parts: subjective experience, an expressive component and physiological arousal.

Emotion may be differentiated from terms such as affect and mood: affect is commonly regarded as an umbrella term that covers emotion, mood and feeling (Bagozzi, Gopinath, \& Nyer, 1999; Cohen, Pham, \& Andrade, 2008); while mood normally refers to an affective state with a low level of intensity, emotions are often described as more intense affective feelings (Cohen et al., 2008; Hosany \& Prayag, 2013). Mood is also generally unrelated to any particular event or situation and is pervasive feeling state (Gardner, 1985). On the other hand, emotions are elicited by a specific referent (e.g. person, event, and situation). For example, a tourist may feel angry when she finds a beach is dirty and crowded; she may feel happy with a tour guide who is patient and friendly.

In light of the complexity of emotion and large numbers of emotion measurement scales used by tourism researchers, it is crucial to briefly outline the theoretical debate in regards to conceptualization of emotion. There are two dominant approaches to research on emotions within tourism and marketing: the basic emotion and dimensional approaches. The basic emotion approach regards emotions, such as happiness, sadness and anger, as discrete entities (Chamberlain \& Broderick, 2007) that are assumed to be present from birth, although there is no consensus about their number or nature (Richins, 1997). The basic emotion approach includes several theories with the majority based on cross-cultural study that suggests a finite 
set of discrete emotions (Lzard, 1992; Plutchik, 1982). Examples of this approach includes the Differential Emotions Scale (Izard, 1977) and the Circular Model of Emotion (Plutchik, 1980). The circular model of emotion identifies eight basic emotions: surprise, expectancy, disgust, acceptance, sadness, joy, anger and fear. As Richins (1997, p. 128) noted, "these eight emotions have adaptive significance in the struggle for survival and are identifiable in some form at all phylogenetic levels in animal kingdom”. In contrast, the differential emotions scale developed by Izard (1977) is based on research examining distinctive facial expressions, and identified 10 basic emotions: guilt, shame/shyness, fear, contempt, disgust, anger, distress, surprise, enjoyment and interest. Both Plutchik and Izard believed that more complicated emotions are mixtures of these basic or primary emotions. In addition, the Consumption Emotion Scale (CES) is also a form of basic emotion theory particularly related to consumption experience, and based on the belief that earlier researchers have overlooked some critical emotions important in consumption situations (Richins, 1997). In particular, a set of 16 consumption emotions descriptors were identified and the usefulness of this descriptor set was confirmed.

The dimensional approach attempts to identify a set of common dimensions of affect that can be utilized to differentiate specific emotions from one another. The two main dimensions used are affective valence and arousal. Valence refers to the pleasantness of an experience, and 'pleasant' and 'unpleasant' usually anchor the continuum of the valence dimension. Arousal, on the other hand, refers to the activation of the internal state, and usually contrasts states of 'quiet' with states of 'excited'. The dimensional approach is intuitive and simple to use to distinguish emotions (Huang, 2001; Larsen \& Diener, 1992). The most popular dimensional approaches applied to consumer behaviour research are the Pleasure Arousal Dominance (P-A-D) model of emotion (Russell, 1980), the Circumplex model (D. Watson \& Tellegen, 1985) and the Positive Affect Negative Affect Schedule (PANAS) (D. Watson, Clark, \& Tellegen, 1988). All these models attempt to simplify the emotional responses by examining a series of common affective dimensions although there are nuances in terms of the name and number of these dimensions.

In recent decades, numerous studies based on dimensional perspective emerged and further confirmed the role of emotion in consumption experience (Chamberlain \& Broderick, 2007). Emotion in marketing is short lived and rarely seen in their pure form, and it is problematic to label consumers' affective state with a specific name as basic emotion approach does (Huang, 
2001). The dimensional approach is believed to be more parsimonious compared with basic emotion approach (Mauss \& Robinson, 2009), when considering that thousands of affective words classified using only a few dimensions. Most emotion studies involving psychophysiological instruments regard emotion as a multi-dimensional construct and assess it by valence and arousal dimension (Gakhal \& Senior, 2008; Hutcherson, 2013; KappelerSetz, Gravenhorst, Schumm, Arnrich, \& Tröster, 2013; Lajante, Droulers, Dondaine, \& Amarantini, 2012; Wang \& Minor, 2008). This is mainly due to the fact that emotion specificity has been hard to establish in the domain of physiology (Mauss \& Robinson, 2009). More specifically, there is no agreement on whether a discrete emotion relates with a special facial behaviour, vocal characteristic or a certain level of skin conductance. In contrast, dimensional frameworks appear to have substantial explanatory value and can better capture human's emotional responses. Given this, dimensional approach to emotion serves as the appropriate theoretical basis for further dicussion on psychophysiological measurement of emotion in this study.

In addition to the basic and dimensions approaches, cognitive appraisal theory (CAT) may be used to explain the mechanism by which emotions are elicited and the multiple antecedents of a particular emotion (Ma, Gao, Scott, \& Ding, 2013). Appraisal theories such as CAT adopt a cognitive model of emotion in which a series of cognitive evaluations of perceptual stimuli are the causal antecedents of a particular emotion (Arnold, 1961; Frijda, 1986; Roseman, 1984). CAT is consistent with valance and level of arousal being important appraisal dimensions in selecting one of multiple pathways by which emotions are elicited. For the purposes of this study on emotion measurement, the mechanisms by which a particular emotion is elicited are not important and we focus on measurement of emotional arousal and valence and its methodological implications.

\section{Current Measures of Emotion in Tourism}

In this section, the paper reviews the methods used in the tourism literature to measure the emotions associated with a tourist experience. The discussion is organised by theoretical approach as there is a strong association between particular theories and methods, although it is also true that the most common method used to capture tourists' emotional responses is self-report method. Self-report methods emphasize introspective reflections about emotions that indicate an individual's subjective feelings (Poels \& Dewitte, 2006). Emotions are 
measured by open-ended questions or a battery of emotion items using Likert scales. In tourism, self-report scales emerging from both the basic emotion and dimensional approaches have been adapted to capture tourists' emotional responses in the tourism context. Tourism researchers usually adapt measures from emotion theorists to fit the specific study context (Hosany \& Gilbert, 2010).

The basic emotion approach is linked to the Consumption Emotion Scale. In one study, eighteen emotional items derived from the Consumption Emotion Scale were used to examine tourist' emotions and the links amongst travel motivations, activities, emotions and satisfaction levels (Pearce \& Coghlan, 2010). Specifically, the respondents were asked to rate both the type and intensity of emotions they feel on an 18-items affective scale (e.g., happy, pleased, irritated, worried, depressed, sad and lonely etc.). The results showed that the overall satisfaction can only reflect part of the emotional variability. Another study using the Consumption Emotion Scale to measure the intensity of consumption emotion found that the intensity of emotion, particularly positive emotion, varied during the course of a festival (Kyle \& Lee, 2012). Similarly, by adopting a 24-items affective scale, the respondents were asked to indicate the extent to which they were feeling each adjective using a 5-point Likerttype scale where 1 = not at all through 5 = extremely much. Izard (1977)'s categorization of emotions is also adapted by tourism researchers to measure consumers' emotional experiences. for example, Jang and Namkung (2009) incorporated four positive emotions (i.e., joy, excitement, peacefulness and refreshment) and five negative emotions (i.e., anger, distress, disgust, fear and shame) into their emotion measurement items, and found that emotion mediated between perceived quality and behavioural intention in a restaurant setting.

Hosany and Gilbert (2010, p. 513) noted that "existing emotion scales are problematic as they fail to take into account tourists' and destinations' specific characteristics” and as a result developed the 'Destination Emotion Scale' (joy, love and positive surprise) representing tourists' emotional experiences toward destinations. The authors also found that tourist's emotions are correlated with satisfactions, which in turns, influences their consumption behaviours. The Destination Emotion Scale (DES) was then used to investigate appraisal determinants of tourists' emotional reactions (Hosany, 2012) and relationships between visitors' emotional patterns and their post-consumption evaluations (Hosany \& Prayag, 2013). They suggested tourists' emotional responses can be generally divided into five patterns (delighted, unemotional, negatives, mixed, and passionate) and further validated the DES 
scale.

Amongst the dimensional models, the Pleasure-Arousal-Dominance (P-A-D) model is most frequently used in the tourism and hospitality literature, and focuses on emotional response to environmental stimuli (Russell \& Mehrabian, 1974). P-A-D uses the three dimensions of pleasure-displeasure, arousal-non-arousal and dominance-submissiveness and is used to measure feelings, moods and other related concepts (Russell, 1980). For example, respondents are often asked to indicate to what extent they feel pleasant or aroused. Sometimes 'pleasure' is measured by positive adjectives such as happy, pleased and satisfied, whereas individuals' level of arousal is indicated by items such as relaxed, calm and excited (A. Yuksel, 2007).

In the tourism and hospitality fields, the P-A-D model has been employed to capture tourists' emotional response and explore how tourists' emotions affect satisfaction and behavioural intentions (J. Enrique Bigné et al., 2005), destination visitation intentions in various nationalities (White \& Scandale, 2005), recreation satisfaction among hunters (Floyd, 1997), destination image (Seyhmus \& David, 1997) and shopping behaviours (Donovan, Rossiter, Marcoolyn, \& Nesdale, 1994; Machleit \& Eroglu, 2000; A. Yuksel, 2007). Specifically, the dimension of pleasure has been positively linked to both satisfaction and loyalty behaviours more so than arousal and dominance dimensions (J Enrique Bigné, Mattila, \& Andreu, 2008; Floyd, 1997). In some cases however, these three dimensions (pleasure-arousal-dominance) have been found to be inadequate in terms of their ability to represent tourists' emotions. Floyd (1997) demonstrated that emotions did not fit the three dimensional structure proposed by the P-A-D model and the arousal dimension was consistently weak in predicting overall satisfaction. In another study the P-A-D model was compared with two other basic emotion models (Izard, 1977; Plutchik, 1980) and found to have the weakest predictive ability to assess emotional responses from shopping experiences (Machleit \& Eroglu, 2000). It may be that the P-A-D model is more useful for predicting behavioural responses at a holiday destination or wilderness area (Ma, 2013), and is better applied to determine tourists' perception of environmental stimuli (Chebat \& Michon, 2003). In other words, the P-A-D model is more useful when the research focuses on the possible underlying dimensions of the emotion experienced by the customers rather than what specific emotion is evoked by external stimulus (Chamberlain \& Broderick, 2007). 
Few tourism studies have employed the Positive And Negative Affect Schedule (PANAS) (D. Watson et al., 1988). PANAS is a 20-item self-report measure of positive and negative emotions. Either positive or negative emotions are further categorized into high and low activation levels (Crawford \& Henry, 2004). In the tourism literature, affective items adapted from a German version of PANAS was used to examine the mediating role of emotion (fear and joy) between personality and satisfaction and demonstrated that individuals' emotions are influenced by personality traits (i.e., neuroticism and extraversion), and in turn impact tourists' satisfaction (Matzler \& Faullant, 2011). Zins (2002) employed nine positive (e.g., satisfied, pleased, and enthusiastic) and nine negative affective items (e.g., upset, angry, and unhappy) derived from PANAS to measure consumers' emotion outcomes in service experience. The results confirmed consumers' emotional responses as important antecedents to their final cognitive evaluation of the entire consumption experience. Table 1 summarizes the articles in the tourism literature discussing tourists' emotion measured by the scales or models mentioned above.

\section{TABLE 1 ABOUT HERE}

\section{Criticisms of self-report}

By and large, it is clear that no matter which approach (i.e., basic emotion or dimensional approach) is employed to examine the emotion in tourism experiences, self-report scales are used. Self-report measures are simple and inexpensive methods to capture individuals' emotional reactions in large-scale studies (Poels \& Dewitte, 2006), and can be utilized to measure either past emotions, anticipated emotions, current emotions, or emotions in general (Jacobs et al., 2012). However, there are limitations in using self-report scales when measuring individuals' emotions. Firstly, self-report measurements can distort a tourist's original emotional responses towards the destination or specific stimuli as the respondents are often asked to recall their emotional experiences after travel. This may involve cognitive intervention and socially desirable responses (Paulhus, 2002). A number of studies have emphasized that people tend to process information automatically without too much cognitive processing on most occasions (Chartrand, 2005; Zaltman, 2003), therefore self-reported indicators may not accurately capture individuals' unprompted and unconscious emotional responses in the initial stage of capturing external stimuli (Kardes, Posavac, \& Cronley, 2004; Micu \& Plummer, 2010). 
Secondly, self-report measures are unable to measure participants' emotional experience in real time (Micu \& Plummer, 2010). Although some marketing studies asked respondents to indicate the strength of their perceived emotions in real time, which was termed 'moment-tomoment ratings' by Poels and Dewitte (2006), such measurement may seriously interfere with the message processing as it happens at a conscious level (N. Ravaja, 2004). Openended questions or a set of affective items ratings do not examine respondents' emotional responses to specific emotional stimuli. Lastly, given most self-report scales always include a long list of affective adjectives (e.g., the 18-items or 24-items affective scale mentioned above), the rating process can be complex and result in fatigue in the participants. This is particularly pertinent for the tourists who are may already be exhausted after a trip or after visiting some tourism attraction.

Emotional data collected by self-report measures captures a consumer's perception of their emotional response rather than the emotional response itself (Poels \& Dewitte, 2006). Therefore, the emotional data collected through traditional self-report methods may pose threats to the reliability and validity of the research results. Given the critiques of self-report measurement of emotion, the paper will discuss several psychophysiological measurements used in advertising, marketing and media research in the following section, which may provide researchers in this field with a more valid and reliable approach to the measurement of tourist emotion.

\section{Psychophysiological Measures for Capturing Tourists' Emotions}

Emotions are accompanied by physiological responses that occur spontaneously and beyond a subject's control. Psychophysiological measures track psychophysiological indicators such as the heartbeat rate and facial muscle movements to identify responses to stimuli (Wang \& Minor, 2008). Compared with traditional self-report measures, psychophysiological measurements can be conducted continuously and are not dependent on language, recall or interference with message processing (N. Ravaja, 2004). Hence, psychophysiological measures avoid cognitive bias caused by mental processing or social desirability constraints. Importantly, they allow continuous measurement providing researchers with a vast number of data points, yielding rich data for comparison of peak versus average response. It is generally advisable to employ multiple psychophysiological measurements rather than a single measure so as to better understand differing response patterns as there is seldom one-to-one 
relationship between psychological state and physiological response in psychophysiology (N. Ravaja, 2004; Wang \& Minor, 2008).

In this section, five psychophysiological methodologies available for tourism researchers in the study of emotion are discussed. As outlined above, the discussion on different psychophysiological methods is closely associated with dimensional approach that structures emotions along dimensions (e.g., valence and arousal). More specifically, the methods introduce here involve three autonomic nervous system (ANS) measures (Electro-dermal analysis, heart rate response and vascular activity) and two somatic nervous system (SNS) measures (facial muscle activity and eye movement tracking). Different measures of emotion are sensitive to different dimensional aspects of state (Mauss \& Robinson, 2009).

\section{Electro-dermal analysis (EDA)}

Electro-dermal analysis (EDA) is the measurement of activation of the Autonomic Nervous System (ANS) that controls most of our organs and muscles and of which we are mostly unconscious (Dawson, Schell, \& Filion, 2007; Jacobs et al., 2012; Poels \& Dewitte, 2006). The ANS is composed of a sympathetic (muscle activation) system and a parasympathetic system (relaxation). For example, the sympathetic system will increase sweat secretion when a tourist suddenly sees a bear during bushwalking, whereas the parasympathetic system will decrease the physiological activities when the threat no longer exists (Jacobs et al., 2012). Electro-dermal activity is one of the most common methods to assess the ANS responses, particularly for the sympathetic system (Mauss \& Robinson, 2009). Physiological arousal leads to activation of the eccrine sweat glands (involved in emotion-evoked sweating) and can be measured by the skin's resistance to or conductance of electric currents (Chamberlain \& Broderick, 2007; Klebba, 1985). In physiological research, skin conductance response (SCR) and galvanic skin response (GSR) are two dominant means for measuring electrodermal activity. In marketing research, skin conductance response (SCR) is more popular and can yield both tonic and phasic data. Tonic data is also called "skin conductance level (SCL)" data, and refers to the base level of skin conductance that differs from one subject to the other. On the other hand, phasic data refers to the short-term change of skin conductance when the individual is exposed to external stimuli. Electro-dermal activity is normally measured by placing two electrodes on the participant's distal phalanx of both forefinger and middle finger of their non-writing hand. Before attaching electrodes to the participants' fingers, participants 
will be asked to wipe their palmar surfaces and fingers to control hydration levels across participants (Paul D Bolls, Lang, \& Potter, 2001).

Electro-dermal activity has been utilized to monitor human's attention (Paul D. Bolls, Muehling, \& Yoon, 2003), the arousal dimension of emotion (Paul D Bolls et al., 2001; Groeppel-Klein \& Baun, 2001; Kappeler-Setz et al., 2013) and warmth (Aaker, Stayman, \& Hagerty, 1986; Abeele \& MacLachlan, 1994). However, only arousal has been reliably validated when measured by electro-dermal response (Klebba, 1985). Several studies conducted by Lang and his colleagues have found that either positive or negative stimulus with different levels of arousal will trigger a change of skin conductance level (SCL) (M. M. Bradley \& Lang, 2000; P. J. Lang, 1995; Peter J Lang, Greenwald, Bradley, \& Hamm, 1993). Self-report arousal level was also compared with the data measured by EDA and is highly correlated, providing support that objective measure of arousal accords with subjective experience (Peter J Lang et al., 1993). EDA also has been found to be correlated with brand attitude. Galvanic skin response (GSR) levels were reduced significantly when participants viewed their preferred brand names (Walla, Brenner, \& Koller, 2011).

The major limitation of EDA is that it cannot determine the valence of the emotion (Gakhal \& Senior, 2008; Hutcherson, 2013; Kappeler-Setz et al., 2013; Lajante et al., 2012; Poels \& Dewitte, 2006; N. Ravaja, 2004; Wang \& Minor, 2008). However, this defect can be addressed by combining EDA with other psychophysiological methods or self-report scales. Furthermore, the placement sites of the device and experiment environment are crucial for the accuracy of the results when performing an EDA measure (Stewart \& Furse, 1982). Additionally, the EDA may need to be measured at differing times to guarantee the reliability of the data (Cacioppo \& Petty, 1983). Compared with self-report scales, EDA is a better and more valid predictor of sales potency of advertising (LaBarbera \& Tucciarone, 1995). EDA measurement requires practice to produce reliable results. Guidelines in the use of EDA methodology are provided by LaBarbera and Tucciarone (1995). They emphasize the importance of sensitive equipment and accurate analysis, and argue that experimental designs should be used. Skin conductance levels differ amongst individuals and standardizing these differences is important (Ben-Shakhar, 1985).

\section{Heart rate response (HR)}


Heart rate response (HR) is the measurement of the number of heart beats in a period of time (normally in one minute) and is the most frequently used method in psychophysiology ( $\mathrm{N}$. Ravaja, 2004). The most common approach to measure heartbeat is through recording electrical potentials produced by the heart during each cardiac cycle using a electrocardiography (ECG) (Turpin, 1986). The measurement of HR is relatively easy and requires almost no disturbance to the subject. HR is usually measured by putting heart rate monitor on the wrist that is close to radial artery (Poels \& Dewitte, 2006). P. J. Watson and Gatchel (1979) contend that HR is a reliable measurement that is not affected by external disturbances, and can be assessed in both laboratory and non-laboratory settings.

HR has been employed to measure the valence of emotion when exposed to various stimuli (Paul D Bolls et al., 2001): HR will increase when one is exposed to positive stimuli and decrease in response to negative stimuli (Cuthbert, Bradleym, \& Lang, 1996). HR is a reliable measure of attention as heart rate is an indispensable part of the psychophysiological attention mechanism (A. Lang, 2002; N. Ravaja, 2004; Wang \& Minor, 2008; P. J. Watson \& Gatchel, 1979). HR decelerates when individuals pay attention to a stimulus or take in information (Annie Lang, 1990; Turpin, 1986). The level of arousal relates to long-term heart rate change and normally an increase in arousal is accompanied by an acceleration of heart rate (Annie Lang, 1990). HR shows high reliability (A. Lang, 2002). However, validity issues must be considered when interpreting a particular psychological activity by heart rate variations, because the variations may be evoked by various psychological processes (Wang \& Minor, 2008). Hopkins and Fletcher (1994) also queried the accuracy of interpreting HR in isolation and suggested that it is better to use HR as a complementary technique to give an indication of valence when it is combined with other autonomic measurements.

\section{Facial muscle activity}

Facial muscle activity is an important physiological indicator of internal psychological activities. Facial muscle activity such as contraction can be measured through electrodes on the skin electronic (Mauss \& Robinson, 2009; Tassinary, Cacioppo, \& Vanman, 2007; Wang \& Minor, 2008). Detailed guidelines for facial muscle activity measurement can be found in Boxtel (2001). In marketing and media research, electromyography (EMG) is the most popular method to measure consumers facial muscle activity. Facial muscle activity has been shown as a successful method to examine the valence of affective response when exposed to 
external stimuli (Paul D Bolls et al., 2001; Groeppel-Klein, 2005; P. J. Lang, 1995; Peter J Lang et al., 1993; Mauss, Levenson, McCarter, Wilhelm, \& Gross, 2005; Mauss \& Robinson, 2009; Wiles \& Cornwell, 1991). Facial electromyography activity is typically recorded at the zygomatic and corrugator sites on the left side of the face by using electrodes. (Fridlund \& Cacioppo, 1986).It is suggested that increased activity at the zygomaticus area (cheek muscle) relates to positive emotions whereas negative emotion involves movements at corrugator supercilii muscle ( It is located at the medial end of the eyebrow) (Peter J Lang et al., 1993), providing a reliable and authentic measure of emotional valence. There is also evidence that the expression of enjoyment, and genuine pleasure are related to increased activity in the orbicularis oculi muscle region (Ekman, Davidson, \& Friesen, 1990; Ritz, George, \& Dahme, 2000). The orbicularis oculi muscle is a ring-like band of muscle, also referred as to a sphincter muscle that encircles the eye. When Hazlett and Hazlett (1999) compared selfreport measures with facial EMG, the later was a more sensitive discriminator of emotional variation and more related to recall. Moreover, increased zygomatic activity can predict the purchasing intention during the decision-making process (Niklas Ravaja \& Somervuori, 2013).

The accuracy of EMG can be influenced by respondents' physical movements and body sensitivity (Paul D Bolls et al., 2001; Poels \& Dewitte, 2006; Wang \& Minor, 2008). Therefore, a well-disguised experiment may be necessary to improve the validity and reliability of facial muscle activity measurement (Wang \& Minor, 2008). In addition, although zygomatic EMG has been proposed in the extensive literature as a valid measurement for positive emotion, it is argued that the most unpleasant stimuli can also increase activity in the zygomatic area (Peter J Lang et al., 1993). Therefore it is advisable that the combination of both orbicularis oculi and zygomatic activity measure are used to identify positive emotions (N. Ravaja, 2004). Measurement of facial EMG is normally conducted in a laboratory and may also create problems with ecological validity (Poels \& Dewitte, 2006). This is particularly true when considering the fact that the participants may feel they are being manipulated by the research and behave unnaturally.

\section{Eye movement analysis}

Eye movement or eye tracking measures often supplement other psychophysiological methods as it is important to know which specific stimulus a subject is looking at when his 
facial muscles move or HR changes. Eye movement measurements record the number of fixations and duration of fixations of the eyes when the participants are exposed to a stimulus (Stewart \& Furse, 1982). Eye movement measure can identify the particular components of external stimuli (e.g. words or images) that receive attention. The measurement of eye movement is performed with an eye-tracking system that can identify the point or specific region the participant is paying attention to in real time. Researchers can keep track of eye and external (environment) data at the same time and acquire a video image of the environment with the superimposed eye-tracking information (N. Ravaja, 2004). Combined with other physiological methods (e.g. EDA or HR), the correlation between specific visual scenes and physiological reactions can be observed.

Eye movement has been found to be related to memory (Krugman, Fox, Fletcher, Fischer, \& Rojas, 1994; Wedel \& Pieters, 2000) and attention (Pieters \& Wedel, 2004). However, as with heart rate measures, the reliability of eye movement measures have been queried on the basis that a psychological basis for its mechanism is not available (Kroeber-Riel, 1979). Pieters, Rosbergen, and Wedel (1999) found that eye movement measures can be impacted by excessive blinking or tears.

\section{Vascular activity}

Vascular activity measures record participants' blood pressure, blood pulse volume and pulse rate, all of which are highly sensitive measures in the studies of fear-related stimuli (Fredrikson \& Öhman, 1979). Blood pressure or blood pulse volume is normally recorded by wrapping an inflatable pressure cuff around respondents' upper arms. Vascular activity has been found to be a reliable measure of arousal and highly related to skin conductance (Frost \& Stauffer, 1987), and this technique is regarded by Zillmann, Katcher, and Milavsky (1972) as the most reliable measure of sympathetic activity provoked by physical exertion. Vascular activity has the advantage of being easily tracked as the measurement device is much less complicated compared to other techniques (Wang \& Minor, 2008). Compared with other autonomic measures, research and application of vascular activity is relatively limited. Sanbonmatsu and Kardes (1988) measured individuals' vascular activity using a blood pressure cuff on the upper arm, and the result demonstrated that individuals may respond to the advertising stimuli differently under various physiological arousal levels. Accurate vascular data requires a number of issues (e.g. cuff size and specific operation of the machine) 
to be addressed (Brownley, Hurwitz, \& Schneiderman, 2000). A summary of the five autonomic techniques used in marketing, advertising, media, psychology and neuroscience is provided in Table 2.

\section{TABLE 2 ABOUT HERE}

\section{Overall evaluation of psychophysiological methodology}

An advantage of psychophysiological measures is that emotional responses can be monitored in real time without significant cognitive bias. In addition, various autonomic measurements have provided valid tools to track spontaneous and unprompted emotions that an individual may not even perceive. However, since one single autonomic response can be the result of different aspects of emotion (e.g. arousal or attention), it may be hard to find a direct correlation between specific aspects related to emotion and a physiological reaction. Hence, the combination of traditional self-report scales with autonomic measures is often used to examine subjects' emotional variations (Bagozzi et al., 1999; Chamberlain \& Broderick, 2007). Although autonomic measures have drawbacks as outlined above, they are more useful in detecting unconscious emotional responses compared with self-report scales (Hazlett \& Hazlett, 1999). While traditional self-report scales remain an useful tool for measuring highorder or conscious emotions (Chamberlain \& Broderick, 2007). Physiological measures of emotion can validate respondents' self-report of their emotional states (Lambie and Marcel (2002). If the two methods provide different results then self-report is generally assumed to be invalid. However, it is necessary to test if the data obtained from psychophysiological experiments in laboratory setting is also valid in a natural environment (N. Ravaja, 2004).

Emotion studies using psychophysiological techniques are not limited only to the laboratory settings. For example, a mobile EDA device was used to measure consumers' affective arousal at the point-of-sale (Groeppel-Klein, 2005). In their study, consumers can move freely in the shopping store and perform the assigned task in the experiments. The research showed that affective arousal measured by wearable EDA sensor is an important indicator of buying behaviour. In particular, the buyers are usually more aroused than non-buyers. Later, another unobtrusive, low-cost and wrist-worn sensor was developed by Ming-Zher, Swenson, and Picard (2010) to assess the long-terms EDA outside the laboratory. More importantly, they found that the distal forearm is a reliable alternative to the traditional palmar sites for 
EDA measures. Therefore, it allows for unobtrusive and continuous EDA measurements during everyday activities, which may provide valuable insights for the researchers who are intended to track consumers’ physiological responses in long term.

\section{Conclusion}

This paper provides an overview of current methods used for measuring tourists' emotions generated by tourism experiences and discusses five psychophysiological techniques available for emotion measurement in the tourism context. A literature review indicates that tourism scholars employ self-report as the primary way to measure tourists' emotional responses to experiences. Although the low cost and timely nature of self-report measurement are welcomed by most tourism researchers, this type of measurement cannot capture emotional responses accurately in all situations as it may trigger cognitive intervention and socially desirable responses. The psychophysiological measurements of emotions discussed here provide alternative sources of insight for tourism researchers, particularly for measuring an individual's subconscious or spontaneous emotional responses. The employment of autonomic measures allows measurement of tourists’ emotional reactions continuously.

However, as Mauss and Robinson (2009, p. 228) noted, "there is no gold standard measure of emotional responding”. Although psychophysiological measures can track nuances of consumers' emotional experiences, they are not without limitations, especially in the interpretation of the psychophysiological data. It appears that the construct of emotion may be best measured using multiple methods (P. Lang, 1988; Mandler, 1975; Rachman, 1978). Thus, it is crucial to combine different measurements together to better understand individual's emotional responses. As is highlighted above, different psychophysiological measures appear sensitive to specific dimensions of emotion. For instance, EDA is sensitive to 'arousal' whereas facial muscle activity has been shown to be a successful method to examine the 'valence' of affective response. The respondent's arousal level can be assessed by using both EDA and HR since both of them monitor participants' emotional arousal. Employing multiple methods to measure emotions is important to achieve valid, reliable and comparable results.

Convergence of self-report and psychophysiological measures offers a potential direction for future research. Specifically, the comparison between traditional self-report scales and 
psychophysiological measures can reveal the difference between individuals' conscious emotional reaction and subconscious emotional response when exposed to external stimulus. Furthermore, autonomic measurement can be regarded as the alternative pathway to validate the reliability of the self-report scales.

Several opportunities for tourism research may be identified. Identification of the particular parts of an experience that elicit an emotion can be accomplished by combining eye-tracking system with an EDA or HR device. The eye-tracking system can reveal the specific areas or points the tourists pay most attention to. By synchronizing eye movement information with the psychophysiological data, researchers can investigate and analyse the correlations between the visual elements of a tour and physiological responses. This type of research can either be conducted in laboratory settings or in the real world, but the research design needs to be carefully considered when performed in natural environments. Secondly, it is advisable to combine self-report with autonomic measures to address the emotional response to the specific situation or stimuli. Bias can be reduced by combining self-report and psychological measures (Wiles \& Cornwell, 1991). Comparison between individuals' self-reported emotions and their data collected by psychophysiological techniques can reveal nuances between conscious emotions that involve more cognitive processing and subconscious emotional responses. The application of psychophysiological measurement may also provide valid ways for both researchers and tourism industry managers to design new products. For example, if managers would like to add more emotion-based stimuli into their experience design, they can present potential visitors with various stimuli and then analyse which elicits high levels of arousal by using EDA. This would allow authentic and objective data of emotional responses to be obtained. Given psychophysiological method can track tourism consumers' emotions continuously, their 'emotional peaks' during exposure to a destination ad can be identified. The scenes or attractions that provoke tourism consumers' emotional peaks may offer valuable insights for destination positioning and the determination of destination image.

Even though the relationship between autonomic measurements and the construct of emotions has been well addressed in fields such as marketing, advertising and media, to the authors' knowledge, only one study by Li et al. (2012) uses behavioural, physiological and psychological tools to measure tourists' interactions with macaques. The several autonomic measures described in this study allow tourism scholars to work at the frontier of emotion 
research. By incorporating with multiple techniques from different disciplines, tourist emotion studies will definitely be advancing a step further.

\section{Reference}

Aaker, D. A., Stayman, D. M., \& Hagerty, M. R. (1986). Warmth in advertising: measurement, impact, and sequence effects. Journal of Consumer Research, 12(4), 365-381. doi: 10.1086/208524

Abeele, P. V., \& MacLachlan, D. L. (1994). Process tracing of emotional responses to TV ads: revisiting the warmth monitor. Journal of Consumer Research, 20(4), 586-600. doi: 10.1086/209372

Aho, S. K. (2001). Towards a general theory of touristic experiences: Modelling experience process in tourism. Tourism Review, 56(3/4), 33 - 37.

Alistair, W. (2006). Tourism and hospitality marketing: fantasy, feeling and fun. International Journal of Contemporary Hospitality Management, 18(6), 482-495. doi: 10.1108/09596110610681520

Arnold, M. B. (1961). Emotion and personality, Vol.1 and 2. New York: Columbia University Press.

Bagozzi, R. P., Gopinath, M., \& Nyer, P. U. (1999). The role of emotions in marketing. Journal of the Academy of Marketing Science, 27(2), 184-206.

Barsky, J., \& Nash, L. (2002). Evoking emotion: affective keys to hotel loyalty. The Cornell Hotel and Restaurant Administration Quarterly, 43(1), 39-46.

Ben-Shakhar, G. (1985). Standardization within individuals: a simple method to neutralize individual differences in skin conductance. Psychophysiology, 22(3), 292-299. doi: 10.1111/j.1469-8986.1985.tb01603.x

Benkenstein, M., Yavas, U., \& Forberger, D. (2003). Emotional and cognitive antecedents of customer satisfaction in leisure services: the case of the Rostock Zoo. Journal of Hospitality \& Leisure Marketing, 10(3-4), 173-184.

Bigné, J. E., \& Andreu, L. (2004). Emotions in segmentation. Annals of Tourism Research, 31(3), 682-696. doi: 10.1016/j.annals.2003.12.018

Bigné, J. E., Andreu, L., \& Gnoth, J. (2005). The theme park experience: An analysis of pleasure, arousal and satisfaction. Tourism Management, 26(6), 833-844. doi: 10.1016/j.tourman.2004.05.006

Bigné, J. E., Anna, S. M., \& Luisa, A. (2008). The impact of experiential consumption cognitions and emotions on behavioral intentions. Journal of Services Marketing, 22(4), 303-315. doi: 10.1108/08876040810881704

Bigné, J. E., Mattila, A. S., \& Andreu, L. (2008). The impact of experiential consumption cognitions and emotions on behavioral intentions. Journal of Services Marketing, 22(4), 303-315.

Bloch, P. H., Sherrell, D. L., \& Ridgway, N. M. (1986). Consumer search: an extended framework. Journal of Consumer Research, 13(1), 119-126.

Bolls, P. D., Lang, A., \& Potter, R. F. (2001). The effects of message valence and listener arousal on attention, memory, and facial muscular responses to radio advertisements. Communication Research, 28(5), 627651.

Bolls, P. D., Muehling, D. D., \& Yoon, K. (2003). The effects of television commercial pacing on viewers' attention and memory. Journal of Marketing Communications, 9(1), 17-28. doi: 10.1080/1352726032000068032

Boxtel, A. v. (2001). Optimal signal bandwidth for the recording of surface EMG activity of facial, jaw, oral, and neck muscles. Psychophysiology, 38(1), 22-34.

Bradley, M. M., \& Lang, P. J. (2000). Measuring emotion: Behavior, feeling, and physiology. In R. D. L. L. Nadel (Ed.), Cognitive neuroscience of emotion (pp. 242-276). New York, NY, US: Oxford University Press.

Bradley, S. D., Angelini, J. R., \& Lee, S. (2007). Psychophysiological and memory effects of negative political ads: Aversive, arousing, and well remembered. Journal of Advertising, 36(4), 115-127.

Brownley, K. A., Hurwitz, B. E., \& Schneiderman, N. (2000). Cardiovascular psychophysiology. New York, NY, US: Cambridge University Press.

Cacioppo, J. T., \& Petty, R. E. (1983). Social psychophysiology: a sourcebook. New York: Guilford Press.

Chamberlain, L., \& Broderick, J. A. (2007). The application of physiological observation methods to emotion research. Qualitative Market Research: An International Journal, 10(2), 199-216. doi: 10.1108/13522750710740853

Chartrand, T. L. (2005). The role of conscious awareness in consumer behavior. Journal of Consumer Psychology, 15(3), 203-210.

Chebat, J.-C., \& Michon, R. (2003). Impact of ambient odors on mall shoppers' emotions, cognition, and spending: a test of competitive causal theories. Journal of Business Research, 56(7), 529-539. 
Cohen, J. B., Pham, M. T., \& Andrade, E. B. (2008). The nature and role of affect in consumer behavior. Handbook of consumer psychology, 297-348.

Crawford, J. R., \& Henry, J. D. (2004). The Positive and Negative Affect Schedule (PANAS): Construct validity, measurement properties and normative data in a large non - clinical sample. British Journal of Clinical Psychology, 43(3), 245-265.

Cuthbert, B. N., Bradleym, M. M., \& Lang, P. J. (1996). Probing picture perception: Activation and emotion. Psychophysiology, 33(2), 103-111.

Davidson, J., Bondi, L., \& Smith, M. (2005). Emotional geographies. Burlington, VT: Ashgate.

Dawson, M. E., Schell, A. M., \& Filion, D. L. (2007). The Electrodermal System. Handbook of psychophysiology, 159.

de Rojas, C., \& Camarero, C. (2008). Visitors' experience, mood and satisfaction in a heritage context: Evidence from an interpretation center. Tourism Management, 29(3), 525-537. doi: 10.1016/j.tourman.2007.06.004

del Bosque, I. R., \& Martín, H. S. (2008). Tourist satisfaction a cognitive-affective model. Annals of Tourism Research, 35(2), 551-573. doi: 10.1016/j.annals.2008.02.006

Donovan, R. J., Rossiter, J. R., Marcoolyn, G., \& Nesdale, A. (1994). Store atmosphere and purchasing behavior. Journal of Retailing, 70(3), 283-294. doi: 10.1016/0022-4359(94)90037-X

Ekman, P., Davidson, R. J., \& Friesen, W. V. (1990). The Duchenne smile: Emotional expression and brain physiology: II. Journal of personality and social psychology, 58(2), 342.

Fernández, C., Pascual, J. C., Soler, J., Elices, M., Portella, M. J., \& Fernández-Abascal, E. (2012). Physiological responses induced by emotion-eliciting films. Applied psychophysiology and biofeedback, 37(2), 73-79. doi: 10.1007/s10484-012-9180-7

Floyd, M. F. (1997). Pleasure, arousal, and dominance: Exploring affective determinants of recreation satisfaction. Leisure Sciences, 19(2), 83-96.

Fredrikson, M., \& Öhman, A. (1979). Cardiovascular and Electrodermal Responses Conditioned to Fear Relevant Stimuli. Psychophysiology, 16(1), 1-7.

Fridlund, A. J., \& Cacioppo, J. T. (1986). Guidelines for human electromyographic research. Psychophysiology, 23(5), 567-589. doi: 10.1111/j.1469-8986.1986.tb00676.x

Frijda, N. H. (1986). The emotions. Cambridge ; New York: Cambridge University Press.

Frost, R., \& Stauffer, J. (1987). The effects of social class, gender, and personality on physiological responses to filmed violence. Journal of Communication, 37(2), 29-45.

Gakhal, B., \& Senior, C. (2008). Examining the influence of fame in the presence of beauty: an electrodermal "neuromarketing" study. Journal of consumer behaviour, 7(4/5), 331-341. doi: 10.1002/cb.255

Gangadharbatla, H., Bradley, S., \& Wise, W. (2013). Psychophysiological Responses to Background Brand Placements in Video Games. Journal of Advertising, 42(2-3), 251-263.

Gardner, M. P. (1985). Mood States and Consumer Behavior: A Critical Review. Journal of Consumer Research, 12(3), 281-300. doi: $10.2307 / 254374$

Goossens, C. (2000). Tourism information and pleasure motivation. Annals of Tourism Research, 27(2), 301-321.

Gretzel, U., Fesenmaier, D. R., Formica, S., \& O'Leary, J. T. (2006). Searching for the future: Challenges faced by destination marketing organizations. Journal of Travel Research, 45(2), 116-126.

Groeppel-Klein, A. (2005). Arousal and consumer in-store behavior. Brain Research Bulletin, 67(5), 428-437.

Groeppel-Klein, A., \& Baun, D. (2001). The Role of Customers' Arousal for Retail Stores--Results from An Experimental Pilot Study Using Electrodermal Activity as Indicator. Advances in consumer research, 28(1), 412-419.

Hazlett, R. L., \& Hazlett, S. Y. (1999). Emotional response to television commercials: Facial EMG vs. self-report. Journal of Advertising Research, 39(2), 7-24.

Holbrook, M. B. (2006). Consumption experience, customer value, and subjective personal introspection: An illustrative photographic essay. Journal of Business Research, 59(6), 714-725.

Hopkins, R., \& Fletcher, J. E. (1994). Electrodermal measurement: Particularly effective for forecasting message influence on sales appeal Measuring psychological responses to media messages (pp. 113-132). Hillsdale, NJ, England: Lawrence Erlbaum Associates, Inc.

Hosany, S. (2012). Appraisal Determinants of Tourist Emotional Responses. Journal of Travel Research, 51(3), 303-314.

Hosany, S., \& Gilbert, D. (2010). Measuring Tourists' Emotional Experiences toward Hedonic Holiday Destinations. Journal of Travel Research, 49(4), 513-526. doi: 10.1177/0047287509349267

Hosany, S., \& Prayag, G. (2013). Patterns of tourists' emotional responses, satisfaction, and intention to recommend. Journal of Business Research, 66(6), 730-737. doi: 
http://dx.doi.org/10.1016/j.jbusres.2011.09.011

Huang, M. H. (2001). The theory of emotions in marketing. Journal of Business and Psychology, 16(2), 239-247. doi: 10.1023/A:1011109200392

Hutcherson, D. E. (2013). Measuring arousal through physiological responses to packaging designs: Investigating the validity of electrodermal activity as a measure of arousal in a realistic shopping environment. (Dissertation/Thesis), Clemson University, Clemson, United States.

Izard, C. E. (1977). Human emotions. New York: Plenum Press.

Jacobs, M. H., Fehres, P., \& Campbell, M. (2012). Measuring Emotions Toward Wildlife: A Review of Generic Methods and Instruments. Human Dimensions of Wildlife, 17(4), 233-247.

Jang, S., \& Namkung, Y. (2009). Perceived quality, emotions, and behavioral intentions: Application of an extended Mehrabian-Russell model to restaurants. Journal of Business Research, 62(4), 451-460. doi: http://dx.doi.org/10.1016/i.jbusres.2008.01.038

Kappeler-Setz, C., Gravenhorst, F., Schumm, J., Arnrich, B., \& Tröster, G. (2013). Towards long term monitoring of electrodermal activity in daily life. Personal and Ubiquitous Computing, 17(2), 261-271. doi: 10.1007/s00779-011-0463-4

Kardes, F. R., Posavac, S. S., \& Cronley, M. L. (2004). Consumer Inference: A Review of Processes, Bases, and Judgment Contexts. Journal of Consumer Psychology, 14(3), 230-256. doi: 10.1207/s15327663jcp1403_6

Klebba, J. M. (1985). Physiological measures of research: A review of brain activity, electrodermal response, pupil dilation, and voice analysis methods and studies. Current issues and research in advertising, 8(1), 53-76.

Kleinginna Jr, P. R., \& Kleinginna, A. M. (1981). A categorized list of emotion definitions, with suggestions for a consensual definition. Motivation and emotion, 5(4), 345-379.

Kroeber-Riel, W. (1979). Activation research: Psychobiological approaches in consumer research. Journal of Consumer Research, 5(4), 240-250.

Krugman, D. M., Fox, R. J., Fletcher, J. E., Fischer, P. M., \& Rojas, T. H. (1994). Do adolescents attend to warnings in cigarette advertising? An eye-tracking approach. Journal of Advertising Research, 34(6), 39-39.

Kwortnik, R. J., \& Ross, W. T. (2007). The role of positive emotions in experiential decisions. International Journal of Research in Marketing, 24(4), 324-335. doi: 10.1016/j.ijresmar.2007.09.002

Kyle, G. T., \& Lee, J. J. (2012). Recollection consistency of festival consumption emotions. Journal of Travel Research, 51(2), 178-190. doi: 10.1177/0047287510394197

LaBarbera, P. A., \& Tucciarone, J. D. (1995). GSR reconsidered: A behavior-based approach to evaluating and improving the sales potency of advertising. Journal of Advertising Research, 35(5), 33-53.

Lajante, M., Droulers, O., Dondaine, T., \& Amarantini, D. (2012). Opening the "Black Box" of Electrodermal Activity in Consumer Neuroscience Research. Journal of Neuroscience, Psychology, and Economics, 5(4), 238-249. doi: 10.1037/a0030680

Lambie, J. A., \& Marcel, A. J. (2002). Consciousness and the varieties of emotion experience: a theoretical framework. Psychological Review, 109(2), 219-259. doi: 10.1037/0033-295X.109.2.219

Lang, A. (1990). Involuntary attention and physiological arousal evoked by structural features and emotional content in TV commercials. Communication Research, 17(3), 275-299.

Lang, A. (2002). Captured by the World Wide Web: orienting to structural and content features of computerpresented information. Communication Research, 29(3), 215-245. doi: 10.1177/0093650202029003001

Lang, P. (1988). What are the Data of Emotion? In V. Hamilton, G. Bower \& N. Frijda (Eds.), Cognitive Perspectives on Emotion and Motivation (Vol. 44, pp. 173-191): Springer Netherlands.

Lang, P. J. (1995). The emotion probe. Studies of motivation and attention. The American psychologist, 50(5), 372-385. doi: 10.1037/0003-066X.50.5.372

Lang, P. J., Greenwald, M. K., Bradley, M. M., \& Hamm, A. O. (1993). Looking at pictures: Affective, facial, visceral, and behavioral reactions. Psychophysiology, 30(3), 261-273.

Larsen, R. J., \& Diener, E. (1992). Promises and problems with the circumplex model of emotion Emotion (pp. 25-29). Thousand Oaks, CA, US: Sage Publications, Inc.

Li, J., Yang, D., He, L., Tao, S., Zeng, L., \& Buckley, R. (2012). Psychological, physiological and behavioural responses of tourists to interactions with rhesus macaques at Zhangjiajie, China. Journal of Ecotourism, 11(3), 202-206.

Lzard, C. E. (1992). Basic Emotions, Relations Among Emotions, and Emotion-Cognition Relations. Psychological Review, 99(3), 561-565. doi: 10.1037/0033-295X.99.3.561

Ma, J. (2013). Emotions derived from theme park experiences: the antecedents and consequences of customer delight. (Dissertation/Thesis), University of Queensland, Brisbane, Australia. 
Ma, J., Gao, J., Scott, N., \& Ding, P. (2013). Customer delight from theme park experiences: The Antecedents of Delight based on Cognitive Appraisal Theory. Annals of Tourism Research, 42(0), 359-381. doi: http://dx.doi.org/10.1016/j.annals.2013.02.018

Machleit, K. A., \& Eroglu, S. A. (2000). Describing and Measuring Emotional Response to Shopping Experience. Journal of Business Research, 49(2), 101-111. doi: 10.1016/S0148-2963(99)00007-7

Mandler, G. (1975). Mind and emotion. New York: Wiley.

Marion G., M., Arvid, K., \& Bettina, O. (2012). Perceiving press photography: a new integrative model, combining iconology with psychophysiological and eye-tracking methods. Visual Communication, 11(3), 307-328. doi: 10.1177/1470357212446410

Mattila, A., \& Wirtz, J. (2000). The role of preconsumption affect in postpurchase evaluation of services. Psychology and Marketing, 17(7), 587-605.

Matzler, K., \& Faullant, R. (2011). Personality, basic emotions, and satisfaction: primary emotions in the mountaineering experience. Tourism Management, 32(6), 1423-1430. doi: 10.1016/j.tourman.2011.01.004

Mauss, I. B., Levenson, R. W., McCarter, L., Wilhelm, F. H., \& Gross, J. J. (2005). The Tie That Binds? Coherence Among Emotion Experience, Behavior, and Physiology. Emotion, 5(2), 175-190. doi: 10.1037/15283542.5.2.175

Mauss, I. B., \& Robinson, M. D. (2009). Measures of emotion: A review. Cognition \& Emotion, 23(2), 209-237. doi: 10.1080/02699930802204677

Mcintosh, A. J., \& Siggs, A. (2005). An exploration of the experiential nature of boutique accommodation. Journal of Travel Research, 44(1), 74-81.

Micu, A. C., \& Plummer, J. T. (2010). Measurable emotions: how television ads really work : patterns of reactions to commercials can demonstrate advertising effectiveness. Journal of Advertising Research, 50(2), 137-153. doi: 10.2501/S0021849910091300

Ming-Zher, P., Swenson, N. C., \& Picard, R. W. (2010). A Wearable Sensor for Unobtrusive, Long-Term Assessment of Electrodermal Activity. IEEE Transactions on Biomedical Engineering, 57(5), 1243-1252. doi: 10.1109/TBME.2009.2038487

Morin, C. (2011). Neuromarketing: The New Science of Consumer Behavior. Society, 48(2), 131-135. doi: 10.1007/s12115-010-9408-1

Niedenthal, P. M., \& Brauer, M. (2012). Social functionality of human emotion. Annual review of psychology, 63(1), 259-285. doi: 10.1146/annurev.psych.121208.131605

Ohme, R., Reykowska, D., Wiener, D., \& Choromanska, A. (2009). Analysis of neurophysiological reactions to advertising stimuli by means of EEG and galvanic skin response measures. Journal of Neuroscience, Psychology, and Economics, 2(1), 21.

Otto, J. E., \& Ritchie, J. R. B. (1996). The service experience in tourism. Tourism Management, 17(3), 165-174. doi: 10.1016/0261-5177(96)00003-9

Parrott, W. G. (2001). Emotions in social psychology: essential readings. Philadelphia: Psychology Press.

Paulhus, D. L. (2002). Socially desirable responding: The evolution of a construct The role of constructs in psychological and educational measurement (pp. 49-69): L. Erlbaum Associates.

Peacock, J., Purvis, S., \& Hazlett, R. L. (2011). Which broadcast medium better drives engagement? Measuring the powers of radio and television with electromyography and skin-conductance measurements. Journal of Advertising Research, 51(4), 578.

Pearce, P., \& Coghlan, A. (2010). Tracking affective components of satisfaction. Tourism and Hospitality Research, 10(1), 42-58. doi: 10.1057/thr.2009.18

Pieters, R., Rosbergen, E., \& Wedel, M. (1999). Visual Attention to Repeated Print Advertising: A Test of Scanpath Theory. Journal of Marketing Research, 36(4), 424-438. doi: 10.2307/3151998

Pieters, R., \& Wedel, M. (2004). Attention capture and transfer in advertising: Brand, pictorial, and text-size effects. Journal of Marketing, 68(2), 36-50.

Plutchik, R. (1980). Emotion: a psychoevolutionary synthesis. New York: Harper \& Row.

Plutchik, R. (1982). A psychoevolutionary theory of emotions. Social Science Information, 21(4-5), 529-553. doi: 10.1177/053901882021004003

Poels, K., \& Dewitte, S. (2006). How to capture the heart? Reviewing 20 years of emotion measurement in advertising. Journal of Advertising Research, 46(1), 18-37. doi: 10.2501/S0021849906060041

Rachman, S. (1978). Human fears: A three systems analysis. Cognitive Behaviour Therapy, 7(4), 237-245.

Ravaja, N. (2004). Contributions of psychophysiology to media research: review and recommendations. Media Psychology, 6(2), 193-235. doi: 10.1207/s1532785xmep0602_4

Ravaja, N., \& Somervuori, O. (2013). Purchase behavior and psychophysiological responses to different price 
levels. Psychology \& marketing, 30(6), 479-489. doi: 10.1002/mar.20621

Richins, M. L. (1997). Measuring emotions in the consumption experience. Journal of Consumer Research, 24(2), 127-146.

Ritz, T., George, C., \& Dahme, B. (2000). Respiratory resistance during emotional stimulation: evidence for a nonspecific effect of experienced arousal? Biological Psychology, 52(2), 143-160.

Roseman, I. J. (1984). Cognitive determinants of emotion: A structural theory. Review of Personality \& Social Psychology, 5(5), 11-36.

Russell, J. A. (1980). A circumplex model of affect. Journal of personality and social psychology, 39(6), 11611178. doi: 10.1037/h0077714

Russell, J. A., \& Mehrabian, A. (1974). An approach to environmental psychology. Cambridge: M.I.T. Press.

Sanbonmatsu, D. M., \& Kardes, F. R. (1988). The effects of physiological arousal on information processing and persuasion. Journal of Consumer Research, 15(3), 379-385.

Seyhmus, B., \& David, B. (1997). Affective images of tourism destinations. Journal of Travel Research, 35(4), 11.

Stewart, D. W., \& Furse, D. H. (1982). Applying psychophysiological measures to marketing and advertising research problems. Current issues and research in advertising, 5(1), 1-38.

Tassinary, L. G., Cacioppo, J. T., \& Vanman, E. J. (2007). The Skeletomotor System: Surface. Handbook of psychophysiology, 267.

Teixeira, T., \& Wedel, M. (2012). Emotion-induced engagement in Internet video advertisements. Journal of Marketing Research, 49(2), 144-159.

Tsaur, S.-H., Chiu, Y.-T., \& Wang, C.-H. (2007). The visitors behavioral consequences of experiential marketing: an empirical study on Taipei Zoo. Journal of Travel \& Tourism Marketing, 21(1), 47-64.

Tung, V. W. S., \& Ritchie, J. R. B. (2011). Exploring the essence of memorable tourism experiences. Annals of Tourism Research, 38(4), 1367-1386. doi: http://dx.doi.org/10.1016/i.annals.2011.03.009

Turpin, G. (1986). Effects of stimulus intensity on autonomic responding: The problem of differentiating orienting and defense reflexes. Psychophysiology, 23(1), 1-14.

Vögele, C. (1995). Cardiovascular reactivity and stress: Patterns of physiological response. Journal of Psychosomatic Research, 39(3), 382-382. doi: 10.1016/0022-3999(95)90139-6

Walla, P., Brenner, G., \& Koller, M. (2011). Objective measures of emotion related to brand attitude: a new way to quantify emotion-related aspects relevant to marketing. PloS one, 6(11), e26782. doi: 10.1371/journal.pone.0026782

Walters, G., \& Sparks, B. (2012). The impact of consumption vision and emotion on the tourism consumer's decision behavior. Journal of hospitality \& tourism research, 36(3), 366-389. doi: $10.1177 / 1096348010390815$

Wang, Y. J., \& Minor, M. S. (2008). Validity, reliability, and applicability of psychophysiological techniques in marketing research. Psychology \& marketing, 25(2), 197-232. doi: 10.1002/mar.20206

Watson, D., Clark, L. A., \& Tellegen, A. (1988). Development and Validation of Brief Measures of Positive and Negative Affect: The PANAS Scales. Journal of personality and social psychology, 54(6), 1063-1070. doi: 10.1037/0022-3514.54.6.1063

Watson, D., \& Tellegen, A. (1985). Toward a consensual structure of mood. Psychological Bulletin, 98(2), 219235.

Watson, P. J., \& Gatchel, R. J. (1979). Autonomic measures of advertising. Journal of Advertising Research, 19(3), 15-26.

Wedel, M., \& Pieters, R. (2000). Eye fixations on advertisements and memory for brands: A model and findings. Marketing science, 19(4), 297-312.

White, C. J., \& Scandale, S. (2005). The Role of Emotions in Destination Visitation Intentions: A Cross-Cultural Perspective. Journal of Hospitality \& Tourism Management, 12(2), 168-178.

Wiles, J. A., \& Cornwell, T. B. (1991). A review of methods utilized in measuring affect, feelings, and emotion in advertising. Current issues and research in advertising, 13(1-2), 241-275.

Yuksel, A. (2007). Tourist shopping habitat: Effects on emotions, shopping value and behaviours. Tourism Management, 28(1), 58-69.

Yuksel, F., Yuksel, A., \& Bilim, Y. (2010). Destination attachment: Effects on customer satisfaction and cognitive, affective and conative loyalty. Tourism Management, 31(2), 274-284. doi: 10.1016/j.tourman.2009.03.007

Zaltman, G. (2003). How customers think: essential insights into the mind of the market. Boston, Mass: Harvard Business School Press.

Zillmann, D., Katcher, A. H., \& Milavsky, B. (1972). Excitation transfer from physical exercise to subsequent aggressive behavior. Journal of Experimental Social Psychology, 8(3), 247-259. 
Zins, A. H. (2002). Consumption Emotions, Experience Quality and Satisfaction: A Structural Analysis for Complainers versus Non-Complainers. Journal of Travel \& Tourism Marketing, 12(2-3), 3-18. doi: 10.1300/J073v12n02_02 
Table 1 Self-report measures in tourism studies

\section{Basic emotion approach}

\begin{tabular}{|c|c|c|}
\hline \multicolumn{3}{|c|}{ Basic emotion approach } \\
\hline Authors & Measures & Major Findings \\
\hline Benkenstein, Yavas, and Forberger (2003) & $\begin{array}{l}\text { Items were adapted from Izard (1971) and Russell } \\
\text { and Snodgrass (1987) }\end{array}$ & $\begin{array}{l}\text { Consumer satisfaction within leisure services is a function of both } \\
\text { cognitive and affective evaluations where the affective evaluations } \\
\text { dominate }\end{array}$ \\
\hline Hosany and Gilbert (2010) & $\begin{array}{l}\text { Destination Emotion Scale (DES): Joy, love, and } \\
\text { positive surprise. }\end{array}$ & $\begin{array}{l}\text { Three dimensions of tourists' emotional experiences toward hedonic } \\
\text { holiday destinations were identified. }\end{array}$ \\
\hline Hosany and Prayag (2013) & $\begin{array}{l}\text { Destination Emotion Scale (DES) : Joy, love, and } \\
\text { positive surprise, and a negative emotion } \\
\text { dimension was added (unpleasantness) }\end{array}$ & $\begin{array}{l}\text { There are five types of tourist's emotional responses: delighted, } \\
\text { unemotional, negatives, mixed, and passionate. }\end{array}$ \\
\hline Hosany (2012) & $\begin{array}{l}\text { Destination Emotion Scale (DES) : Joy, love, and } \\
\text { positive surprise. }\end{array}$ & $\begin{array}{l}\text { Appraisals of pleasantness, goal congruence, and internal self- } \\
\text { compatibility are the cognitive appraisal dimensions of DES. }\end{array}$ \\
\hline Pearce and Coghlan (2010) & Adapted version of consumption emotion set (CES) & $\begin{array}{l}\text { There are links between travel motivations, activities, emotions and } \\
\text { satisfaction levels in tourists }\end{array}$ \\
\hline Kyle and Lee (2012) & Consumption emotion set (CES) & $\begin{array}{l}\text { Examined the construct validity of consumption emotions scale within } \\
\text { festival settings; the intensity of consumption emotion measured by } \\
\text { CES scale was proved inconsistent over time in a festival context }\end{array}$ \\
\hline Jang and Namkung (2009) & Izard (1977)'s categorization of emotions & $\begin{array}{l}\text { Emotion was identified as the mediating variable between perceived } \\
\text { quality and behavioral intention in the restaurant setting }\end{array}$ \\
\hline \multicolumn{3}{|c|}{ Dimensional approach } \\
\hline J. Enrique Bigné et al. (2005) & $\begin{array}{l}\text { P-A-D model proposed by Russell (1980): twelve } \\
\text { items in pleasure and arousal dimensions }\end{array}$ & $\begin{array}{l}\text { The relationship between emotion, satisfaction and behavioral } \\
\text { intentions was identified. }\end{array}$ \\
\hline White and Scandale (2005) & P-A-D model proposed by Russell (1980) & $\begin{array}{l}\text { Emotions were the strongest predictor of visitation intention in } \\
\text { various nationalities. }\end{array}$ \\
\hline Floyd (1997) & $\begin{array}{l}\text { Pleasure, arousal, and dominance adopted from P- } \\
\text { A-D model proposed by Russell (1980) }\end{array}$ & $\begin{array}{l}\text { The role of emotion in predicting recreation satisfaction among the } \\
\text { hunters was proved. }\end{array}$ \\
\hline Seyhmus and David (1997) & Russell’s P-A-D model proposed by Russell (1980) & $\begin{array}{l}\text { Application of P-A-D model has confirmed the importance of } \\
\text { affective image in positioning of tourism destination }\end{array}$ \\
\hline Donovan et al. (1994) & Russell’s P-A-D model proposed by Russell (1980) & $\begin{array}{l}\text { Customers' emotions during the shopping experience were } \\
\text { measured and arousal was found to vary in its effects } \\
\text { whereas pleasantness was a significant predictor of willingness to } \\
\text { spend time and money }\end{array}$ \\
\hline Mattila and Wirtz (2000) & $\begin{array}{l}\text { Two dimensions of P-A-D model: pleasure and } \\
\text { arousal }\end{array}$ & $\begin{array}{l}\text { Pleasure and arousal, these two dimensions can determine the post- } \\
\text { purchase evaluations. }\end{array}$ \\
\hline de Rojas and Camarero (2008) & $\begin{array}{l}\text { Pleasure (six measuring items) was based on the } \\
\text { scale of proposed by Russell (1980) }\end{array}$ & $\begin{array}{l}\text { There is a significant relationship between perceived quality and } \\
\text { emotion. }\end{array}$ \\
\hline Chebat and Michon (2003) & P-A-D model from Russell (1974) and Lazarus' & The cognitive theory of emotions can better explain the effect of \\
\hline
\end{tabular}




\begin{tabular}{|c|c|c|}
\hline & (1991) cognitive theory of emotions. & environmental stimuli on customers' emotion and spending. \\
\hline Machleit and Eroglu (2000) & $\begin{array}{l}\text { Compare Izard (1977) and Plutchik (1980) } \\
\text { emotional scales with Russell's P-A-D model }\end{array}$ & $\begin{array}{l}\text { Russell's model has the lowest predictive ability to describe and } \\
\text { assess the emotional response to shopping environments. }\end{array}$ \\
\hline A. Yuksel (2007) & Russell's P-A-D model & $\begin{array}{l}\text { The emotional response elicited by the shopping environment was } \\
\text { found to impact willingness to talk to salespeople, revisit intentions. }\end{array}$ \\
\hline J. Enrique Bigné, Anna, and Luisa (2008) & Pleasure dimension of Russell’s P-A-D model & $\begin{array}{l}\text { Pleasure dimension has been proved to be positively linked to both } \\
\text { satisfaction and loyalty behaviors }\end{array}$ \\
\hline Matzler and Faullant (2011) & $\begin{array}{l}\text { German version of PANAS (positive affect and } \\
\text { negative affect) }\end{array}$ & $\begin{array}{l}\text { Individuals' emotions are most influenced by neuroticism and } \\
\text { extraversion, separately, which in turn impact tourist satisfaction. }\end{array}$ \\
\hline del Bosque and Martín (2008) & $\begin{array}{l}\text { Positive and negative emotions with different } \\
\text { intensity level }\end{array}$ & $\begin{array}{l}\begin{array}{l}\text { Tourist's expectation and emotion are } \\
\text { satisfactions. }\end{array} \\
\end{array}$ \\
\hline Zins (2002) & The combination of PANAS and Circumplex scale & Emotions have an influence on experience quality and satisfaction \\
\hline
\end{tabular}


Table 2 Summary of Psychophysiological Techniques used in Marketing, Advertising and Media Research

\begin{tabular}{|c|c|c|}
\hline \multicolumn{3}{|c|}{ Psychophysiological measures } \\
\hline \multicolumn{3}{|c|}{ Electro-dermal activity (EDA) } \\
\hline Authors & Methods & Major findings \\
\hline Paul D. Bolls et al. (2003) & $\begin{array}{l}\text { Skin conductance activity experiment was } \\
\text { conducted to assess the level of attention and } \\
\text { memory }\end{array}$ & $\begin{array}{l}\text { Fast-paced ads may have a positive effect on customers' automatic } \\
\text { attention towards an advertisement compared with slow-pace ones }\end{array}$ \\
\hline Groeppel-Klein (2005) & Phasic Electro-dermal reaction (EDR) & $\begin{array}{l}\text { Store atmosphere can elicit phasic arousal responses to attract } \\
\text { consumers }\end{array}$ \\
\hline Paul D Bolls et al. (2001) & $\begin{array}{l}\text { Facial EMG, HR and skin conductance data were } \\
\text { collected to explore the valence and arousal of the } \\
\text { listeners }\end{array}$ & Arousal is better than valence for predicting individuals' memory. \\
\hline Groeppel-Klein and Baun (2001) & Electro-dermal activity (EDA) & $\begin{array}{l}\text { Electro-dermal activity (EDA) proves to be a valid and also very } \\
\text { sensitive indicator that clearly responds to the smallest variation in } \\
\text { arousal. }\end{array}$ \\
\hline Abeele and MacLachlan (1994) & GSR measurement & $\begin{array}{l}\text { SCR was assessed for participants' level of arousal; foot placement of } \\
\text { the EDA device is suitable for recordings in daily life with moderate } \\
\text { movement. }\end{array}$ \\
\hline M. M. Bradley and Lang (2000) & Description and summary & $\begin{array}{l}\text { Either positive or negative stimulus with different level of arousal will } \\
\text { trigger the change of Skin conductance level }\end{array}$ \\
\hline $\begin{array}{lll}\text { Ohme, } \quad \text { Reykowska, } & \text { Wiener, } & \text { and } \\
\text { Choromanska (2009) } & & \end{array}$ & EEG and skin conductance & $\begin{array}{l}\text { Psychophysiological methods can register minor difference between } \\
\text { two ads }\end{array}$ \\
\hline Peter J Lang et al. (1993) & $\begin{array}{l}\text { Self-report, Facial expression ,heart rate and skin } \\
\text { conductance measures }\end{array}$ & $\begin{array}{l}\text { Compared self-report with arousal level by EDA and found they are } \\
\text { highly correlated with each other, giving support that the objective } \\
\text { measure of arousal is in accordance with subjective experience }\end{array}$ \\
\hline Fernández et al. (2012) & $\begin{array}{l}\text { Skin conductance level (SCL), heart rate (HR) and } \\
\text { subjective emotional reactions were measured for } \\
\text { each film clip. }\end{array}$ & $\begin{array}{l}\text { Film clips with discrete emotions were able to trigger measurable } \\
\text { objective physiological reactions. }\end{array}$ \\
\hline Walla et al. (2011) & $\begin{array}{l}\text { Electromyography (EMG), skin conductance and } \\
\text { their heart rate were recorded }\end{array}$ & $\begin{array}{l}\text { Galvanic skin response (GSR) level was significantly reduced when } \\
\text { the participants view their liked brand name. At the same time, the } \\
\text { other physiological techniques such as heart rate and EMG also reflect } \\
\text { the results. }\end{array}$ \\
\hline LaBarbera and Tucciarone (1995) & Galvanic skin response (GSR) measure & EDA is a better and more valid predictor of market performance \\
\hline Peacock, Purvis, and Hazlett (2011) & Facial electromyography \& skin conductance & $\begin{array}{l}\text { Compared with radio advertising, TV ads evoke more negative } \\
\text { emotions }\end{array}$ \\
\hline
\end{tabular}




\begin{tabular}{|c|c|c|}
\hline \multicolumn{3}{|c|}{$\begin{array}{ll}\text { Heart rate measure (HR) } \\
\end{array}$} \\
\hline Paul D Bolls et al. (2001) & $\begin{array}{l}\text { Facial EMG, HR and skin conductance data were } \\
\text { collected to explore the valence and arousal of the } \\
\text { listeners }\end{array}$ & $\begin{array}{l}\text { HR data indicates that negative stimuli receive more attention than } \\
\text { positive ones }\end{array}$ \\
\hline Cuthbert et al. (1996) & Skin conductance, HR and EMG were measured & $\begin{array}{l}\text { HR will increase when exposed to positive stimuli whereas the } \\
\text { negative situations will be accompanied by decrease of HR }\end{array}$ \\
\hline A. Lang (2002) & Heart rate response & $\begin{array}{l}\text { Animated banner advertisements have been proved to cause cardiac- } \\
\text { orienting reactions among attentive individuals (computer users) }\end{array}$ \\
\hline Annie Lang (1990) & $\begin{array}{l}\text { Heart rate data were collected to assess the level of } \\
\text { arousal and attention }\end{array}$ & $\begin{array}{l}\text { HR decelerates when individuals pay attention to a stimulus or take in } \\
\text { information; and arousal relates more with long-term heart rate } \\
\text { change and normally the increase of arousal is accompanied by a tonic } \\
\text { acceleration }\end{array}$ \\
\hline Turpin (1986) & Heart rate response & $\begin{array}{l}\text { HR measures need to be combined with other autonomic methods to } \\
\text { guarantee the reliability of the results }\end{array}$ \\
\hline Gangadharbatla, Bradley, and Wise (2013) & Heart rate and skin conductance measure & $\begin{array}{l}\text { Game players can unconsciously notice the background } \\
\text { advertisements in video games }\end{array}$ \\
\hline \multicolumn{3}{|c|}{ Facial muscle activity } \\
\hline Boxtel (2001) & $\begin{array}{l}1 \text { minute facial EMG recordings were selected } \\
\text { (divide into } 60 \text { data segments) }\end{array}$ & $\begin{array}{l}\text { Jaw, oral, and neck muscles were examined and it is found that } \\
\text { different muscles varied when exposed to external stimulus }\end{array}$ \\
\hline Paul D Bolls et al. (2001) & $\begin{array}{l}\text { EDA, HR and Facial EMG data were collected } \\
\text { during the exposure to ADs }\end{array}$ & EMG is a reliable tool to measure the valence of the emotions. \\
\hline Mauss et al. (2005) & $\begin{array}{l}\text { Two coders worked separately to rate individuals’ } \\
\text { facial expressions }\end{array}$ & $\begin{array}{l}\text { Results from self-report scales and psychophysiological measures } \\
\text { showed that participants' physiological responses were only modestly } \\
\text { correlated with experience and behaviour. }\end{array}$ \\
\hline Peter J Lang et al. (1993) & $\begin{array}{l}\text { Skin conductance, facial expression and interest } \\
\text { ratings }\end{array}$ & $\begin{array}{l}\text { Facial expression measures support the view that different affects } \\
\text { have differing patterns of reactivity }\end{array}$ \\
\hline Ritz et al. (2000) & $\begin{array}{l}\text { Facial EMGs (corrugator supercilii, orbicularis } \\
\text { oculi, and masseter) }\end{array}$ & $\begin{array}{l}\text { The expression of enjoyment smile and genuine pleasure are related to } \\
\text { increased activity at the orbicularis oculi muscle region }\end{array}$ \\
\hline Hazlett and Hazlett (1999) & $\begin{array}{l}\text { Comparison between self-report and EMG } \\
\text { measures }\end{array}$ & $\begin{array}{l}\text { Self-report measure was compared with facial EMG, and it is found } \\
\text { that facial EMG was a more sensitive discriminator of emotional } \\
\text { variation and more related to recall. }\end{array}$ \\
\hline Niklas Ravaja and Somervuori (2013) & $\begin{array}{l}\text { Facial electromyography (EMG) and Electro- } \\
\text { dermal activity were recorded }\end{array}$ & $\begin{array}{l}\text { Increased zygomatic activity can predict the purchasing intention } \\
\text { during decision-making process }\end{array}$ \\
\hline S. D. Bradley, Angelini, and Lee (2007) & Facial electromyography (EMG): eye blink startle & 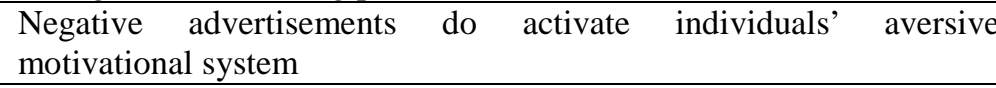 \\
\hline \multicolumn{3}{|c|}{$\begin{array}{l}\text { Eye movement analysis } \\
\end{array}$} \\
\hline Krugman et al. (1994) & $\begin{array}{l}\text { Eye tracking device records point of gaze, fixation, } \\
\text { and saccades }\end{array}$ & Eye movement has been proved to be related to recall and memory \\
\hline
\end{tabular}




\begin{tabular}{|c|c|c|}
\hline Wedel and Pieters (2000) & $\begin{array}{l}\text { Eye-movement data collected when respondents } \\
\text { were exposed to ads }\end{array}$ & Memory is positively related to eye movement activity \\
\hline Pieters and Wedel (2004) & $\begin{array}{l}\begin{array}{l}\text { Eye-tracking data recorded from ad elements } \\
\text { (brand, pictorial, and text) }\end{array} \\
\end{array}$ & The image is superior in capturing individuals' attention \\
\hline Pieters et al. (1999) & Eye -tracking methodology for print ads & $\begin{array}{l}\text { Participant's attention level decreased when that are presented } \\
\text { repetitive print ads }\end{array}$ \\
\hline Hutcherson (2013) & $\begin{array}{l}\text { Physiological responses (EDA and eye-tracking) to } \\
\text { packaging designs }\end{array}$ & $\begin{array}{l}\text { Data collected from EDA and eye-tracking shows insignificant } \\
\text { relationships when exposed to emotional stimulus }\end{array}$ \\
\hline Teixeira and Wedel (2012) & $\begin{array}{l}\text { Facial Actions Coding System and eye-tracking } \\
\text { system }\end{array}$ & $\begin{array}{l}\text { Joy and surprise increase viewers' concentration of attention and } \\
\text { retention in advertisements }\end{array}$ \\
\hline Marion G., Arvid, and Bettina (2012) & Eye-tracking & $\begin{array}{l}\text { A visual communication process model is built to connect various } \\
\text { factors of the communication process }\end{array}$ \\
\hline \multicolumn{3}{|c|}{ Vascular activity } \\
\hline Sanbonmatsu and Kardes (1988) & $\begin{array}{l}\text { The effects of physiological arousal (mainly blood } \\
\text { pressure) on persuasion are investigated }\end{array}$ & $\begin{array}{l}\text { The result is in accordance with elaboration likelihood model that } \\
\text { endorser status has more influence on brand attitudes under high } \\
\text { physiological arousal. }\end{array}$ \\
\hline Frost and Stauffer (1987) & $\begin{array}{l}\text { Blood pulse volume and skin conductance were } \\
\text { recorded to assess possible factors affecting } \\
\text { affective arousal when exposed to media violence }\end{array}$ & $\begin{array}{l}\text { Participants live in inner-city had significantly higher level of arousal } \\
\text { than the college sample through viewing ten types of violent videos }\end{array}$ \\
\hline
\end{tabular}

